\section{Medically unexplained symptoms: are we making progress?}

The BJGP editorial and associated papers ${ }^{1-4}$ about medically unexplained symptoms (MUS) do not consider dissociation, beyond a passing reference to hysteria. Dissociation is any detachment from surroundings or from physical and emotional experiences, and can be regarded as a coping mechanism. ${ }^{5}$ The previous use of 'functional', to describe MUS, implies a dissociative disorder.

Up to $10 \%$ of the population has a form of dissociative disorder, ${ }^{6}$ which could account for many of the thorny issues we encounter daily in general practice. This might include eating disorders, substance abuse, derealisation, somatisation, trauma, fibromyalgia, chronic pain, and compliance.

There is increasing understanding of the role dissociation has in post-traumatic stress disorder (PTSD), ${ }^{7}$ which also throws light on the development of adult difficulties relating to childhood abuse and trauma. Childhood issues are more prevalent among people with MUS; the Lamahewa et al paper here shows $26 \%$ for abuse and $32 \%$ for trauma. ${ }^{2}$

Not surprisingly for what is accepted as a mixed bag of illness and aetiologies, the meta-analysis of cognitive behavioural interventions for people with MUS shows only weak effects. ${ }^{3}$ Using trauma or a short dissociation screen ${ }^{8}$ could be a useful way to differentiate pathways for management of unexplained somatic disorders in primary care.

Formally identifying dissociative disorders, complex PTSD, and childhood trauma or abuse among those with MUS, then developing strategies to support people more appropriately, ${ }^{9}$ may provide a fruitful way forward for this stubbornly difficult part of general practice.

Sarah C Evans,

GP, Herts Urgent Care.

Email: sarahevans78dahotmail.com

\section{REFERENCES}

1. Malterud K, Aamland A. Medically unexplained symptoms: are we making progress? Br J Gen Pract 2019; DOl: https://doi.org/10.3399/bjgp19X701885.

2. Lamahewa K, Buszewicz M, Walters K, et al. Persistent unexplained physical symptoms: a prospective longitudinal cohort study in UK primary care. Br J Gen Pract 2019; DOI: https://doi. org/10.3399/bjgp19X701249

3. Jones B, Williams AC de C. CBT to reduce healthcare use for medically unexplained symptoms: systematic review and meta-analysis. Br J Gen Pract 2019; DOI: https://doi.org/10.3399/ bjgp19X701273.

4. Gol J, Terpstra T, Lucassen $P$, et al. Symptom management for medically unexplained symptoms in primary care: a qualitative study. Br J Gen Pract 2019; DOI: https://doi.org/10.3399/bjgp19X701849.

5. Wikipedia. Dissociation (psychology). https:// en.wikipedia.org/wiki/Dissociation_(psychology) (accessed 8 May 2019).

6. Wikipedia. Dissociative disorder. https://en.wikipedia org/wiki/Dissociative_disorder laccessed 8 May 2019).

7. Levine PA. Waking the tiger: healing trauma the innate capacity to transform overwhelming experiences. Berkeley, CA: North Atlantic Books, 1997.

8. Wikipedia. Dissociative Experiences Scale. https:// en.wikipedia.org/wiki/ Dissociative_Experiences_ Scale laccessed 8 May 2019).

9. Kennedy F, Kennerley H, Pearson D, eds. Cognitive behavioural approaches to the understanding and treatment of dissociation. London: Routledge, 2013.

DOI: https://doi.org/10.3399/bjgp19X703853

\section{Standardised}

\section{emergency inhaled treatment packs for asthma and COPD}

We invite comments from primary care on a proposal made in an article in Lancet Respiratory Medicine that patients with asthma and COPD who have had, or are at risk of having, an exacerbation should be given standardised emergency inhaled treatment packs containing the appropriate pMDI or pMDIs (salbutamol for COPD, salbutamol and beclomethasone $250 \mathrm{mcg}$ for asthmal and a spacer. These packs, with simple instructions for their use, should be kept sealed and separate from the patient's routine inhaled treatment and used if the person was experiencing an attack that was not responding, with advice to call the GP practice or 111 if the pack was opened. Other oral treatments for exacerbations could also be given at the clinician's discretion.
We think this would lead to better outcomes of exacerbation self-management and fewer emergency department attendances and admissions. It might contribute to a reduction in avoidable deaths.

Advantages: first, patients would have immediate access in an emergency to the most effective possible method for the self-administration of high-dose inhaled treatments. Second, every patient would have been taught how to use these treatments correctly. Third, the task of teaching selfmanagement of exacerbations would be greatly simplified for health professionals since there would be one standardised set of advice for the inhaled treatments for asthma and one for COPD. Fourth, this consistency of message would increase patient confidence and would facilitate widespread public and professional awareness of the key elements of safe and effective inhaled selfmanagement. Fifth, with a move towards more use of dry-powder inhalers for routine treatment on environmental grounds, this would ensure that patients using DPIs for routine treatment retained access to pMDI/ spacer for the treatment of exacerbations not responding to usual therapy.

All changes in practice take work, but we think this would end up saving time in primary care by simplifying the task of self-management education and by helping achieve better treatment outcomes.

The article can be accessed without charge provided you register with the journal online. Let us know what you think - either by letter to the BJGP, by email to duncan.keeleyd nhs.net, or by writing to Lancet Respiratory Medicine.

Duncan Keeley,

GP, Thames.

Email: duncan.keeley99lagmail.com

\section{Martyn Partridge,}

Emeritus Professor of Respiratory Medicine, National Heart and Lung Institute, Imperial College London.

\section{REFERENCE}

1. Keeley D, Partridge M. Emergency MDI and spacer packs for asthma and COPD. Lancet Respir Med 2019; http://dx.doi.org/10.1016/S2213-2600(19)30046-

DOI: https://doi.org/10.3399/bjgp19X703865 